\title{
Numerical Investigation on Double Shell-Pass Shell-and-Tube Heat Exchanger with Continuous Helical Baffles
}

\author{
Shui Ji, Wen-jing Du, Peng Wang, and Lin Cheng \\ Institute of Thermal Science \& Technology, Shandong University, Jinan 250061, China \\ Correspondence should be addressed to Lin Cheng, cheng@sdu.edu.cn
}

Received 1 November 2010; Revised 16 March 2011; Accepted 11 May 2011

Academic Editor: Y. Peles

Copyright () 2011 Shui Ji et al. This is an open access article distributed under the Creative Commons Attribution License, which permits unrestricted use, distribution, and reproduction in any medium, provided the original work is properly cited.

A double shell-pass shell-and-tube heat exchanger with continuous helical baffles (STHXCH) has been invented to improve the shell-side performance of STHXCH. At the same flow area, the double shell-pass STHXCH is compared with a single shell-pass STHXCH and a conventional shell-and-tube heat exchanger with segmental baffles (STHXSG) by means of numerical method. The numerical results show that the shell-side heat transfer coefficients of the novel heat exchanger are $12-17 \%$ and $14-25 \%$ higher than those of STHXSG and single shell-pass STHXCH, respectively; the shell-side pressure drop of the novel heat exchanger is slightly lower than that of STHXSG and 29-35\% higher than that of single shell-pass STHXCH. Analyses of shell-side flow field show that, under the same flow rate, double shell-pass STHXCH has the largest shell-side volume average velocity and the most uniform velocity distribution of the three STHXs. The shell-side helical flow pattern of double shell-pass STHXCH is more similar to longitudinal flow than that of single shell-pass STHXCH. Its distribution of fluid mechanical energy dissipation is also uniform. The double shell-pass STHXCH might be used to replace the STHXSG in industrial applications to save energy, reduce cost, and prolong the service life.

\section{Introduction}

A variety of heat exchangers are used in industries, such as shell-and-tube heat exchangers (STHX), plate-fin heat exchangers, and fin-and-tube heat exchangers. More than 35$40 \%$ of heat exchangers are of the shell-and-tube type due to their robust geometry construction, easy maintenance, and possible upgrades $[1,2]$. However, the traditional STHX with segmental baffles (STHXSG) has many disadvantages such as large back mixing, fouling, high leakage flow, and large cross-flow. Especially, segmental baffles bring on significant pressure drop across the exchanger when changing the direction of flow [3,4]. Over the past decades, different kinds of baffles have been developed, for example, the conventional segmental baffles with different arrangements, the deflecting baffles, the overlap helical baffles, and the rod baffles [5-10].

For STHX with continuous helical baffles (STHXCH), the shell-side flow passes a periodic helical path under the action of baffles. Compared to the conventional STHXSG, STHXCH has some advantages such as reduced shell-side fouling, increased heat-transfer-rate-to-pressure-drop ratio, reduced bypass effects, and prevention from flow-induced vibration [11, 12]. Lutcha and Nemcansky [11] give two reasons accounting for the improvement of heat exchangers performance with helical baffles: firstly, a near plug flow is formed in the shell side which can increase temperature difference for heat transfer, and, secondly, the rotational flow induced by helical baffles creates a vortex which interacts with the boundary layer on the tube surface and favorably affects the heat transfer coefficient.

Some researches $[13,14]$ indicated that the larger the helix angle, the better shell-side comprehensive performance of STHXCH when helix angle is less than $45^{\circ}$. However, a large helix angle, or in other words a large helix pitch, has some adverse effects: first, the shell-side velocity becomes small under the same mass flow rate, which goes against heat transfer; second, the quantity of helical cycle is small, which means the helix flow is possibly not fully developed until it reaches the shell-side outlet; third, the unsupported span on the tube bundles is large, which is not favorable for the prevention of fluid-induced vibration in the shell side [14]. To overcome the aforementioned drawbacks of 


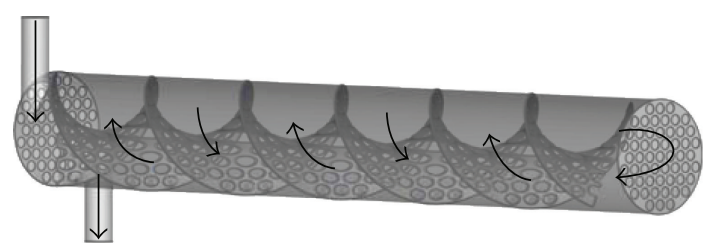

(a) Double shell-pass STHXCH

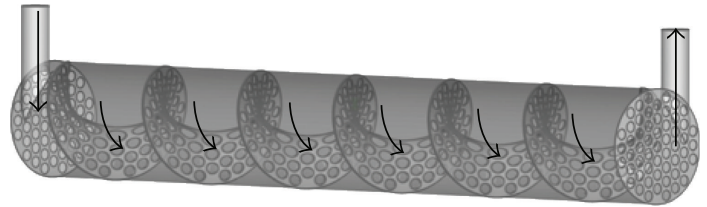

(b) Single shell-pass STHXCH

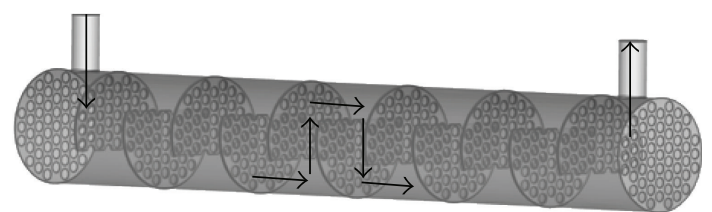

(c) STHXSG

Figure 1: Physical models and flow direction.

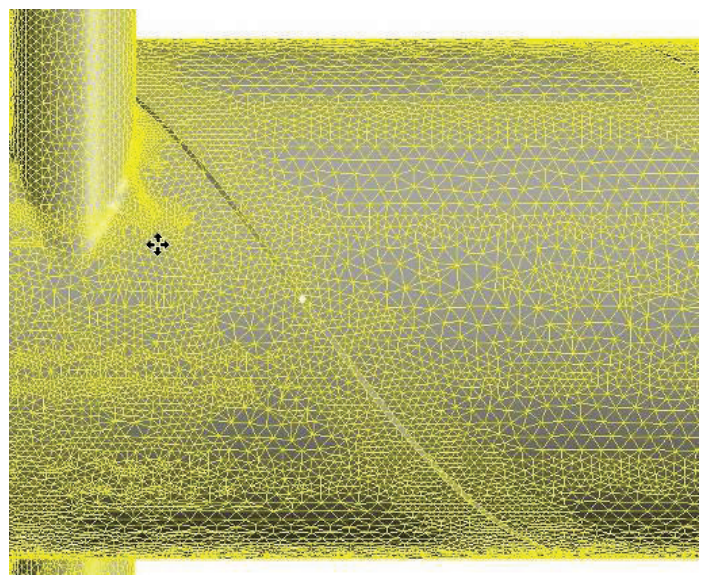

Figure 2: Local meshes of computational model.

STHXCH with large helix angles, a new type of double shellpass STHXCH is invented in this paper. At the same helix angle and shell diameter, the helix pitch and flow area of double shell-pass STHXCH become half of those of single shell-pass STHXCH. In order to validate the advantages of double shell-pass STHXCH, its performance has been compared with that of a conventional STHXSG and single shellpass STHXCH by numerical method.

\section{Physical Model}

Physical models for the computational domain are depicted in Figure 1. Three models have the same heat transfer area and shell-side flow area. The geometric parameters are summarized in Table 1.

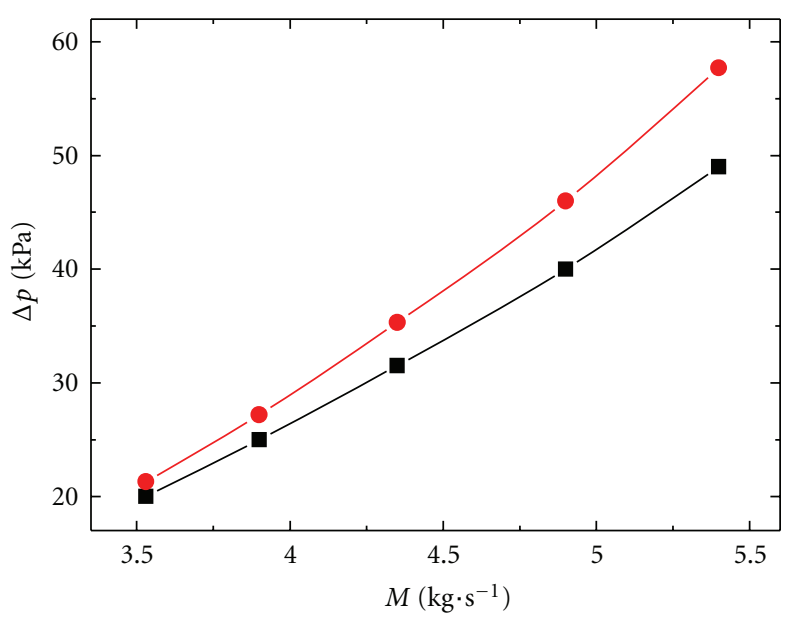

(a) Overall pressure drop

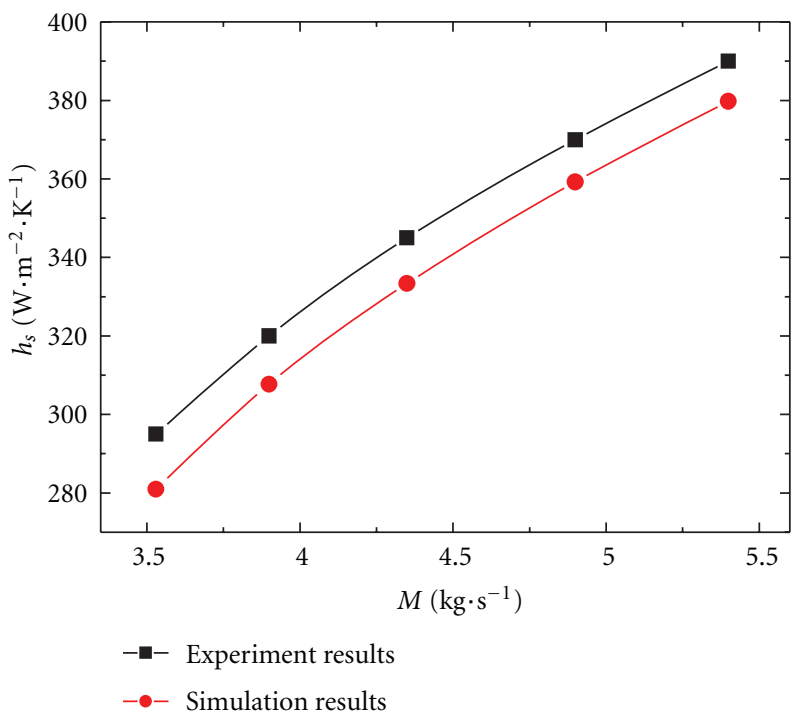

(b) Heat transfer coefficient

FIGURE 3: Comparison experimental results and simulation results in shell side.

\section{Numerical Model and Simulation Method}

3.1. Governing Equations. The renormalization group (RNG) $k-\varepsilon$ turbulence model is adopted because it can provide improved predictions of near-wall flows and flows with high streamline curvature [15]. The general governing equation is as follows:

$$
\frac{\partial\left(\rho u_{i} \Phi\right)}{\partial x_{i}}=\frac{\partial}{\partial x_{i}}\left(\Gamma \frac{\partial \Phi}{\partial x_{i}}\right)+S .
$$

The (RNG) $k-\varepsilon$ turbulence model governing equations are as follows:

$$
\begin{gathered}
\frac{\partial\left(\rho k u_{i}\right)}{\partial x_{i}}=\frac{\partial}{\partial x_{j}}\left(\alpha_{k} \mu_{\mathrm{eff}} \frac{\partial k}{\partial x_{j}}\right)+G_{k}+\rho \varepsilon \\
\frac{\partial\left(\rho \varepsilon u_{i}\right)}{\partial x_{i}}=\frac{\partial}{\partial x_{\mathrm{j}}}\left(\alpha_{\varepsilon} \mu_{\mathrm{eff}} \frac{\partial \varepsilon}{\partial x_{j}}\right)+\frac{C_{1}^{*}}{k} G_{k}-C_{2} \rho \frac{\varepsilon^{2}}{k} .
\end{gathered}
$$


TABLE 1: Geometric parameters of STHXs.

\begin{tabular}{|c|c|c|c|}
\hline Item & STHXCH & STHXCH & STHXSG \\
\hline Shell inside diameter (mm) & 207 & 207 & 207 \\
\hline Tube outside diameter ( $\mathrm{mm}$ ) & 19 & 19 & 19 \\
\hline Tube pitch $(\mathrm{mm})$ & 25 & 25 & 25 \\
\hline Length of tubes $l(\mathrm{~mm})$ & 1500 & 1500 & 1500 \\
\hline Number of tubes & 55 & 55 & 55 \\
\hline Helix angle $\left({ }^{\circ}\right)$ & 36 & 20 & \\
\hline Helix pitch (mm) & 472.5 & 236.7 & \\
\hline Baffle pitch (mm) & & & 118.5 \\
\hline Flow area $\left(\mathrm{m}^{2}\right)$ & $7.44 e-3$ & $7.44 e-3$ & $7.44 e-3$ \\
\hline Shell pass & Double & Single & Single \\
\hline
\end{tabular}

For continuity equation, $\Phi=1$, generalized diffusion coefficient $\Gamma=0$, and source term $S=0$; for momentum equation, $\Phi=u, v, w$, generalized diffusion coefficient $\Gamma=\mu_{\mathrm{eff}}=$ $\mu+\mu_{t}$, and source term $S=-\partial p / \partial x_{i}+\partial / \partial x_{i}\left(\mu_{\text {eff }}\left(\partial u_{i} / \partial x_{j}\right)\right)$; for energy equation, $\Phi=T$, generalized diffusion coefficient $\Gamma=(\mu / \operatorname{Pr})+\left(\mu_{t} / \sigma_{T}\right)$, and source term $S=0$. Other relative parameters are as follows: $\mu_{t}=\rho C_{\mu} \mu\left(k^{2} / \varepsilon\right), C_{\mu}=0.0845$, $\alpha_{k}=\alpha_{\varepsilon}=1.39, C_{1}^{*}=C_{1}-\left(\eta\left(1-\eta / \eta_{0}\right) /\left(1+\beta \eta^{2}\right)\right), C_{1}=1.42$, $C_{2}=1.68, \eta=\left(2 E_{i j} \cdot E_{i j}\right)^{1 / 2}(k / \varepsilon), E_{i j}=1 / 2\left(\left(\partial u_{i} / \partial x_{j}\right)+\right.$ $\left.\left(\partial u_{j} / \partial x_{i}\right)\right), \eta_{0}=4.377$, and $\beta=0.012$, among which $\mu$ is viscosity coefficient, $\operatorname{Pr}$ is Prandtl number, $\sigma_{T}$ is turbulent Prandtl number, $p$ is pressure, $T$ is temperature, and $u, v$, and $w$ are velocity components.

3.2. Basic Assumptions and Boundary Conditions. To simplify the numerical simulation while still keeping the basic characteristics of the process, the following assumptions are made: (1) both the fluid flow and heat transfer processes are turbulent and in steady state; (2) the leakage flow between the tube and the baffle and that between the baffle and the shell are neglected; (3) effects of gravity and buoyancy forces are neglected; (4) the tube wall temperatures are kept constant in the whole shell side; (5) the heat exchanger is well insulated hence, the heat loss to the environment is totally neglected; (6) and the working fluid is heat-transfer oil. Its viscosity changes in a large extent with the variation of temperature, and hence a quadratic function is fitted between viscosity and temperature, and the other physical properties are regarded as constant.

The shell-side inlet is set as velocity inlet with a prescribed flow rate and temperature $\left(T_{\text {in }}=80^{\circ} \mathrm{C}\right)$. The outlet port is set as a pressure boundary condition, which means that a static pressure and a proper backflow are specified. The temperature of the tube walls is set as a constant of $40^{\circ} \mathrm{C}$ and the other surfaces are set as nonslip, adiabatic, and impermeable.

3.3. Mesh Generation and Numerical Method. Due to the complicated structure of STHXCH, the computational domain is meshed with unstructured tetrahedral and pyramidal elements which are generated by ICEM 12.0. Mesh adoption is also used for refining and coarsening local mesh

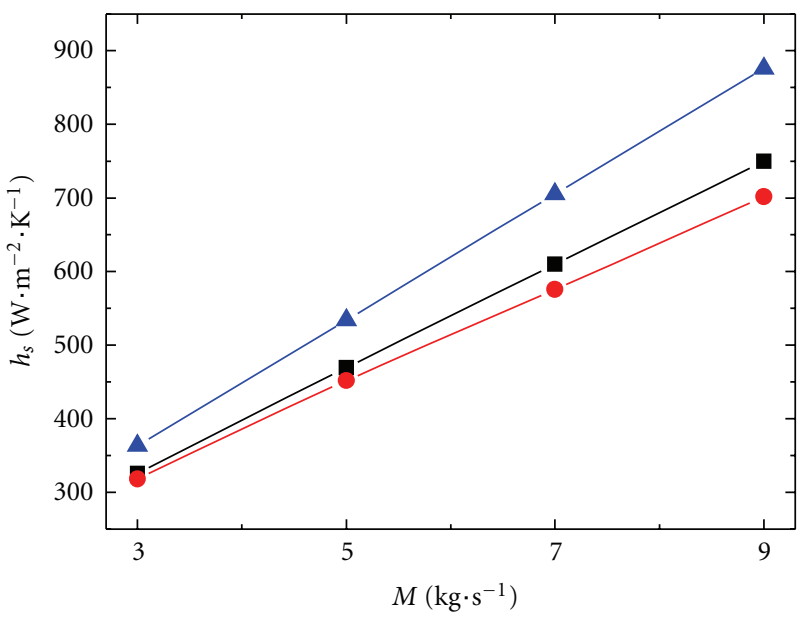

(a) Heat transfer rate $Q_{s}$ versus flow rate

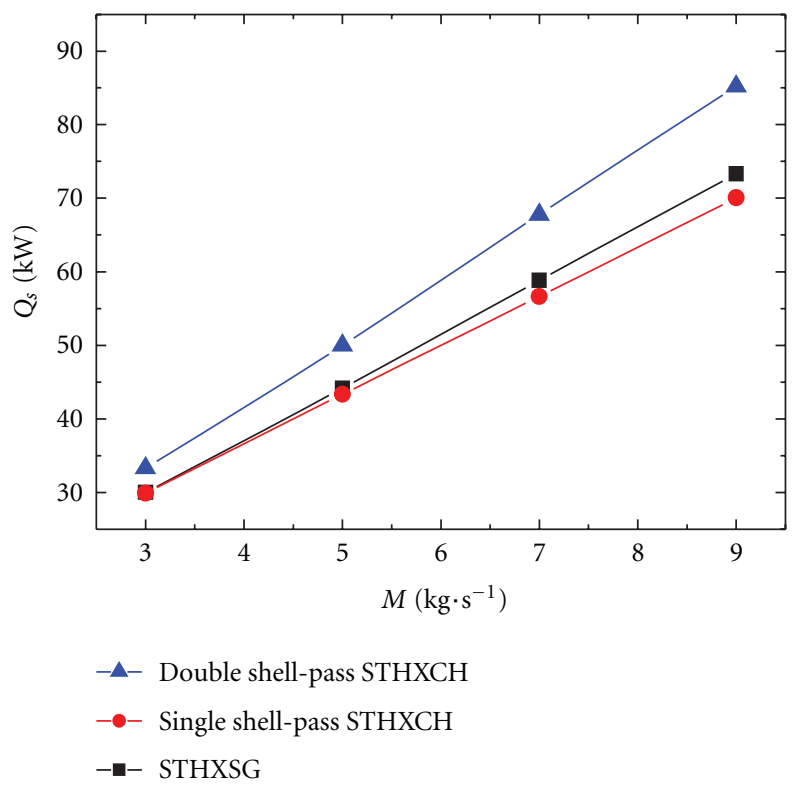

(b) Heat transfer coefficient $h_{s}$ versus flow rate

FIgURE 4: Shell-side heat transfer performance. 


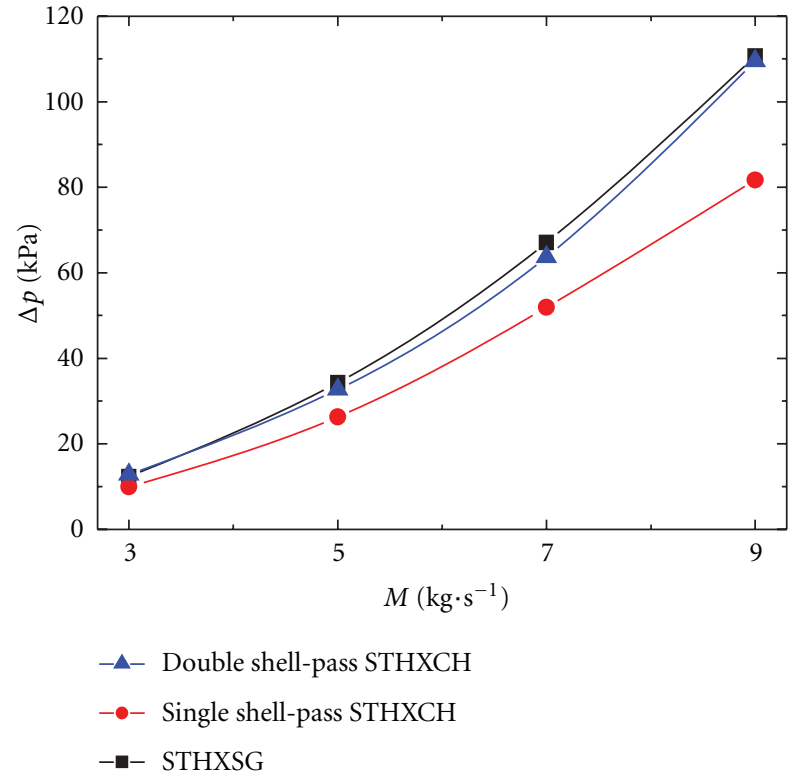

FIGURE 5: Shell-side pressure drop versus flow rate.

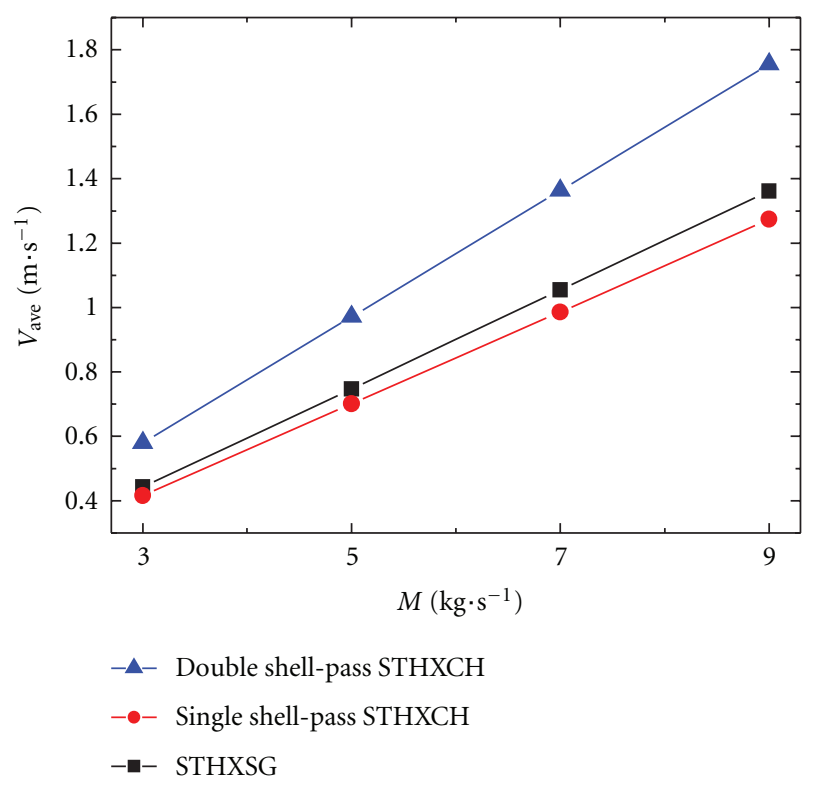

FIGURE 6: Shell side volume average velocity versus flow rate.

according to gradient of variables. In order to ensure the accuracy of numerical results, a careful test for the mesh in-dependence of the numerical solutions was conducted. In the test, three different mesh systems with 9.8 million, 13.6 million, and 17.8 million elements are adopted for calculation of the whole heat exchanger, and the difference in the overall pressure drop and the shell-side heat transfer coefficient between the last two mesh systems is less than $2 \%$. The local meshes and velocity distributions are shown in Figure 2.

The commercial code ANSYS CFX 12.0 is adopted to simulate the flow and heat transfer in the computational model. The governing equations are discredited by the finite

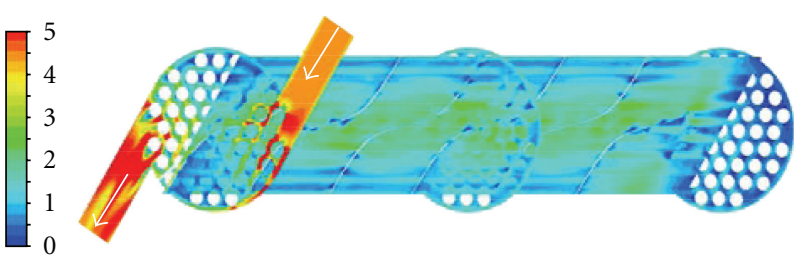

(a) Double shell-pass STHXCH

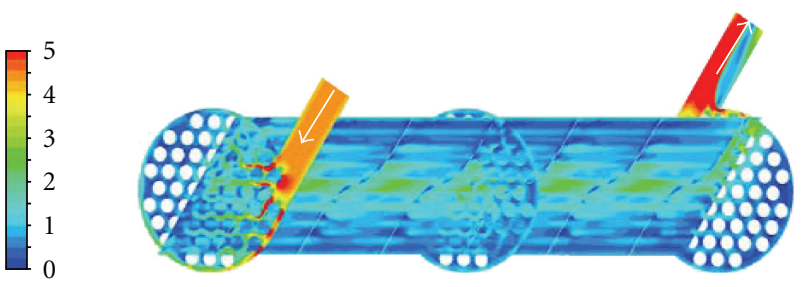

(b) Single shell-pass STHXCH
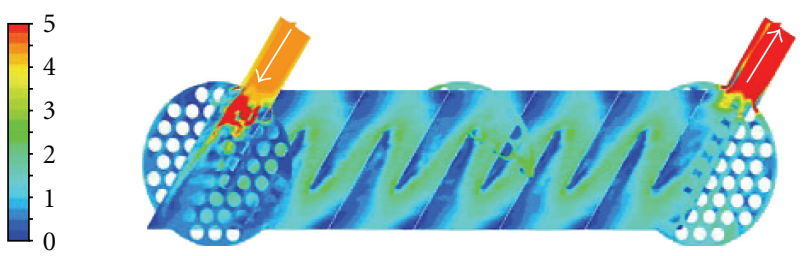

(c) STHXSG

Figure 7: Velocity distributions $\left(M=7 \mathrm{~kg} \cdot \mathrm{s}^{-1}\right)$ (unit: $\left.\mathrm{m} \cdot \mathrm{s}^{-1}\right)$.

volume method. The convergence criterion is that the flow field and mass residual should be less than $10^{-6}$ for the energy residual less than $10^{-7}$ for the energy equation. A parallel computation is performed on four DELL workstations with two Quad-Core CPUs and 16 GB memory each by using $\mathrm{CFX}$, and every simulation case takes approximately $36 \mathrm{~h}$ to get converged solutions.

3.4. Validation of Numerical Method. Validation of the numerical method was made using experimental results from the literature [16]. Figure 3 provides the comparisons between experimental date and simulation results using the numerical method in this paper. It can be observed that for both fluid pressure drop and heat transfer their variation trends with mass flow rate in good agreement. Quantitatively, the difference in pressure drop is $6.5 \%$ $17.8 \%$ and the difference in the heat transfer coefficients ranges $2.7 \% \sim 5.1 \%$. Obviously the numerical method in this paper is reliable and applicable.

\section{Results and Discussion}

4.1. Heat Transfer and Pressure Drop. Heat exchanger rate $Q_{s}$ of shell-side fluid is as follows:

$$
Q_{s}=M_{s} \times c_{p s} \times\left(t_{s, \text { in }}-t_{s, \text { out }}\right) .
$$




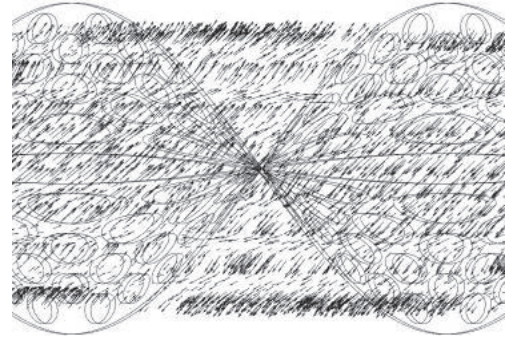

(a) Double shell-pass STHXCH

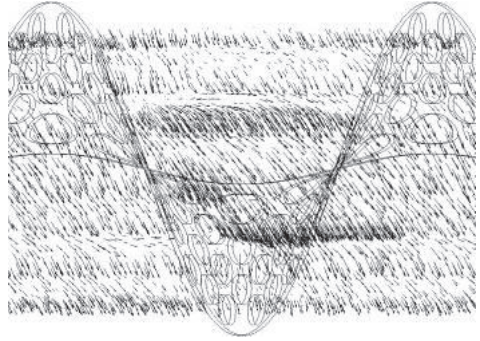

(b) Single shell-pass STHXCH

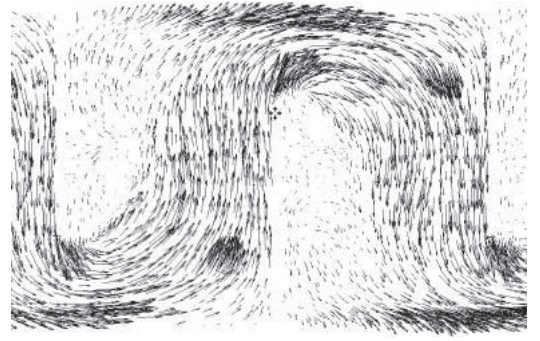

(c) STHXSG

FIGURE 8: Local velocity vector distributions on axial sections of shell ( $M=7 \mathrm{~kg} / \mathrm{s})$.

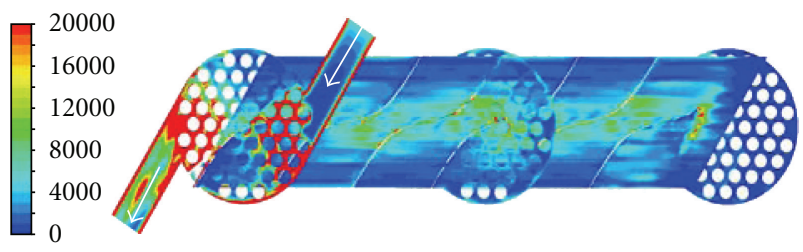

(a) Double shell-pass STHXCH
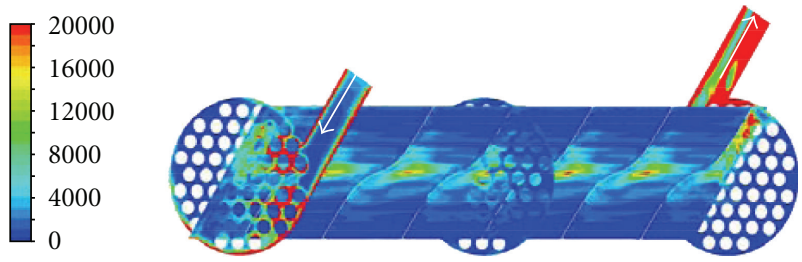

(b) Single shell-pass STHXCH
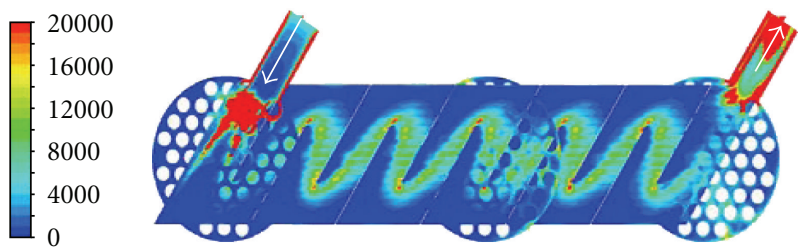

(c) STHXSG

Figure 9: Mechanical energy dissipation rate $E_{D}$ distributions $(M=$ $7 \mathrm{~kg} \cdot \mathrm{s}^{-1}$ ) (unit: $\mathrm{W} \cdot \mathrm{m}^{-3}$ ).

The shell-side heat transfer coefficient $h_{s}$ is equal to

$$
\begin{gathered}
h_{s}=\frac{Q_{s}}{A_{o} \cdot \Delta t_{m}}, \\
A_{o}=N_{t} \cdot \pi d_{o} l, \\
\Delta t_{m}=\frac{\Delta t_{\max }-\Delta t_{\min }}{\ln \left(\Delta t_{\max } / \Delta t_{\min }\right)}, \\
\Delta t_{\max }=t_{s, \text { in }}-t_{w}, \\
\Delta t_{\min }=t_{s, \text { out }}-t_{w},
\end{gathered}
$$

where $A_{o}$ is the heat exchange area based on the outer diameter of tube $d_{o}, N_{t}$ is the number of tubes, $l$ is the effective length of tubes, $t_{w}$ is the temperature of tube walls and the subscripts $s$ and $t$ refer to shell side and tube side, respectively.
The variation trends of shell-side heat transfer and pressure drop with mass flow rate are shown in Figures 4 and 5. It can be seen that, at the same mass flow rate and flow area, the shell-side heat transfer coefficients and heat transfer rate of double shell-pass STHXCH are $12-17 \%$ and $14-25 \%$ higher than those of STHXSG and single shell-pass STHXCH, respectively; the shell-side pressure drop of double shell-pass STHXCH is slightly lower than that of STHXSG and 29-35\% higher than that of single shell-pass STHXCH.

4.2. Flow Field Analysis. In Figure 6 the shell-side volume average velocity data are presented. It can be clearly observed that the shell-side volume average velocity of double shellpass STHXCH is much higher than those of the other two types of STHX in spite of the same flow rate and flow area. That is one of the reasons why double shell-pass STHXCH has the best heat transfer performance.

The velocity distributions of the three STHXs are shown in Figure 7 with same mass flow rate. It can be found that there is nearly no back flow regions and dead zones existed in the shell pass of STHXCHs. The velocity distribution of double shell-pass STHXCH is the most uniform of three STHXs.

The local velocity vector distributions on the axial sections of shell are shown in Figure 8. For both STHXCH, the shell-side fluids pass through the tube bundles basically in a helical pattern and rush the heat exchange tubes with an inclination angle. On the one hand, helical flow avoids abrupt turns of flow. On the other hand, it changes the crosssection shape of tube in flow direction into ellipse. Therefore, it can reduce the pressure drop in shell side and the vibration of tube bundle. It also can be found that, in each shellpass of double shell-pass STHXCH, the flow directions are opposite totally. In addition, the angle between flow direction and axis of tube of double shell-pass STHXCH is much smaller than that of single shell-pass STHXCH. It means that the double shell-pass STHXCH is more similar to the longitudinal flow heat exchanger than the single shell-pass STHXCH. For STHXSG, the shell-side fluid passes through the tube bundles in a dramatic zigzag pattern, which causes large flow resistance and high risk of vibration failure on tube bundle. Furthermore, obvious dead zones are formed at the corners between baffles and shell wall. Flow stagnation in dead zones goes against heat transfer and increases fouling resistance. Therefore, the shell-side pressure drop of double 
shell-pass STHXCH angles is slightly lower than that of STHXSG.

4.3. Mechanical Energy Dissipation. Viscousness of the fluid leads to internal friction when the fluid flows. It is the fundamental reason of the generation of flow resistance. Fixed walls or another type of solid surfaces provide the conditions for the production of flow resistance. The final effect of flow resistance is the dissipation of fluid mechanical energy. Within a (RNG) $k-\varepsilon$ approach for turbulent and steady flow, the local mechanical energy dissipation rate $E_{D}$ of fluid elements is formed by two parts. They are

$$
E_{D}=E_{\bar{D}}+E_{D^{\prime}}
$$

The first term $E_{\bar{D}}$ is equal to viscous dissipation rate $\Phi$, which is calculated by local time-averaging velocity and fluid dynamic viscosity. The second term $E_{D^{\prime}}$ can be calculated by

$$
E_{D^{\prime}}=\rho \cdot \varepsilon
$$

as shown in [17]. Here $\varepsilon$ is the local turbulent dissipation rate, calculated with a $k-\varepsilon$ turbulence model. The $E_{D}$ distributions of the three STHXs are shown in Figure 9. It can be seen that, in flow full-developed region, the $E_{D}$ distribution of double shell-pass STHXCH is the most uniform of the three STHXs. For single shell-pass STHXCH, the fluid mechanical energy dissipation concentrated in the central region of the shell. For STHXSG, dissipation of fluid mechanical energy concentrated in cross-flow tube banks region of the shell.

4.4. Comprehensive Performance. Figure 10 provides the comparison of shell-side heat transfer coefficient and heat transfer rate among the three types of STHX within the range of pressure drop tested.

It can be found from Figure 10 that under the same pressure drop, the shell-side heat transfer coefficient of double shell-pass STHXCH is $11-18 \%$ and $5-13 \%$ higher than that of single shell-pass STHXCH and STHXSG, respectively. Then, the double shell-pass STHXCH has the best shellside comprehensive performance and the STHXSG has the worst shell-side comprehensive performance. The double shell-pass STHXCH might be used to replace the STHXSG in industrial applications to save energy, reduce cost, and prolong the service life.

\section{Conclusion}

In this paper, a novel double shell-pass STHXCH is investigated with numerical method and compared with a single shell-pass STHXCH and a STHXSG. Three models have the same shell-side flow area. The conclusions are summarized as follows: (1) under the same flow rate, the shell side heat transfer coefficient of double shell-pass STHXCH is 14-25\% and $12-17 \%$ higher than that of STHXSG and single shellpass $\mathrm{STHXCH}$, respectively; the shell-side pressure drop of double shell-pass STHXCH is $29-35 \%$ higher than that of single shell-pass STHXCH and slightly lower than that of STHXSG. (2) Under the same shell side pressure drop,

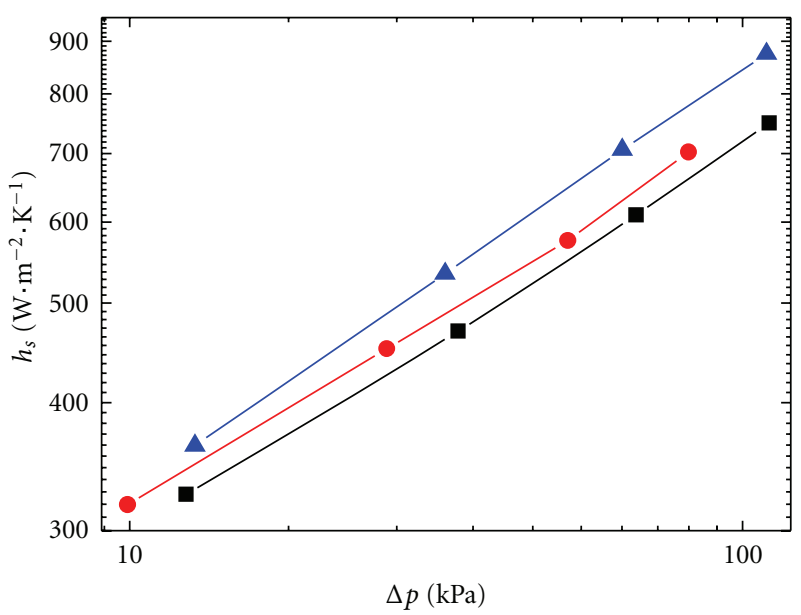

(a) Shell-side heat transfer coefficient versus pressure drop

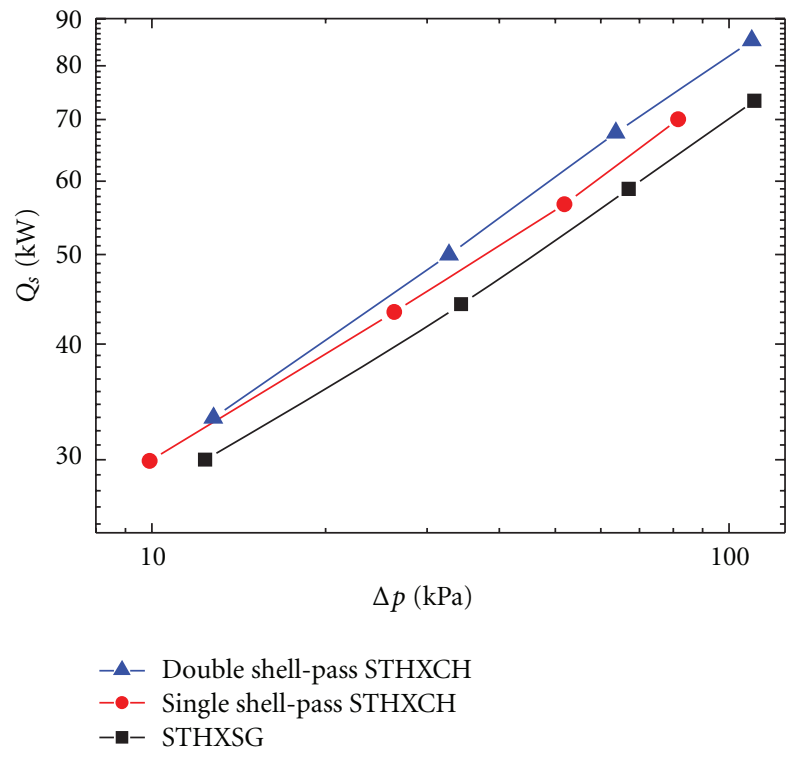

(b) Shell-side heat transfer rate versus pressure drop

FIGURE 10: Shell-side comprehensive performance.

the shell-side volume average velocity of double shell-pass STHXCH is the highest and the velocity distribution is the most uniform. (3) In flow full-developed region of double shell-pass STHXCH, the distribution of fluid mechanical energy dissipation rate is uniform in the three STHXs. (4) Under the same pressure drop, double shell-pass STHXCH has the best heat transfer performance.

\section{Acknowledgment}

The authors would like to acknowledge the financial support from the National Basic Research Program of China (973 Program) (no. 2007CB206900).

\section{References}

[1] K. J. Bell, "Heat exchanger design for the process industries," Journal of Heat Transfer, vol. 126, no. 6, pp. 877-885, 2004. 
[2] B. I. Master, K. S. Chunangad, A. J. Boxma, D. Kral, and P. Stehlík, "Most frequently used heat exchangers from pioneering research to worldwide applications," Heat Transfer Engineering, vol. 27, no. 6, pp. 4-11, 2006.

[3] H. Li and V. Kottke, "Effect of the leakage on pressure drop and local heat transfer in shell-and-tube heat exchangers for staggered tube arrangement," International Journal of Heat and Mass Transfer, vol. 41, no. 2, pp. 425-433, 1998.

[4] H. Li and V. Kottke, "Visualization and determination of local heat transfer coefficients in shell-and-tube heat exchangers for staggered tube arrangement by mass transfer measurements," Experimental Thermal and Fluid Science, vol. 17, no. 3, pp. 210-216, 1998.

[5] P. Stehlík and V. V. Wadekar, "Different strategies to improve industrial heat exchange," Heat Transfer Engineering, vol. 23, no. 6, pp. 36-48, 2002.

[6] H. Li and V. Kottke, "Effect of baffle spacing on pressure drop and local heat transfer in shell-and-tube heat exchangers for staggered tube arrangement," International Journal of Heat and Mass Transfer, vol. 41, no. 10, pp. 1303-1311, 1998.

[7] R. L. Webb and N. H. Kim, Principles of Enhanced Heat Transfer, Taylor \& Francis, Boca Raton, Fla, USA, 2005.

[8] E. A. Vasil'Tsov, "Turbulence of flow in mixers with deflecting baffles," Chemical and Petroleum Engineering, vol. 24, no. 3-4, pp. 111-115, 1988.

[9] C. C. Gentry, "RODbaffle heat exchanger technology," Chemical Engineering Progress, vol. 86, no. 7, pp. 48-57, 1990.

[10] Q. W. Dong, Y. Q. Wang, and M. S. Liu, "Numerical and experimental investigation of shellside characteristics for RODbaffle heat exchanger," Applied Thermal Engineering, vol. 28, no. 7, pp. 651-660, 2008.

[11] J. Lutcha and J. Nemcansky, "Performance improvement of tubular heat exchangers by helical baffles," Chemical Engineering Research and Design, vol. 68, no. 3, pp. 263-270, 1990.

[12] Q. Wang, G. Chen, Q. Chen, and M. Zeng, "Review of Improvements on shell-and-tube heat exchangers with helical baffles," Heat Transfer Engineering, vol. 31, no. 10, pp. 836-853, 2010.

[13] Y. G. Lei, Y. L. He, R. Li, and Y. F. Gao, "Effects of baffle inclination angle on flow and heat transfer of a heat exchanger with helical baffles," Chemical Engineering and Processing: Process Intensification, vol. 47, no. 12, pp. 2336-2345, 2008.

[14] S. Ji, W. J. Du, and L. Cheng, "Numerical investigation on heat transfer and flow properties in shell-side of heat exchanger with continuous helical baffles," Proceedings of the Chinese Society of Electrical Engineering, vol. 29, no. 32, pp. 66-70, 2009.

[15] V. Yakhot and L. M. Smith, "The renormalization group, the $\varepsilon$-expansion and derivation of turbulence models," Journal of Scientific Computing, vol. 7, no. 1, pp. 35-61, 1992.

[16] H. U. Yan, Numerical Simulation of Shell-and-Tube Heat Exchanger, Harbin Institute of Technology, Harbin, China, 2007.

[17] F. Kock and H. Herwig, "Local entropy production in turbulent shear flows: a high-Reynolds number model with wall functions," International Journal of Heat and Mass Transfer, vol. 47, no. 10-11, pp. 2205-2215, 2004. 

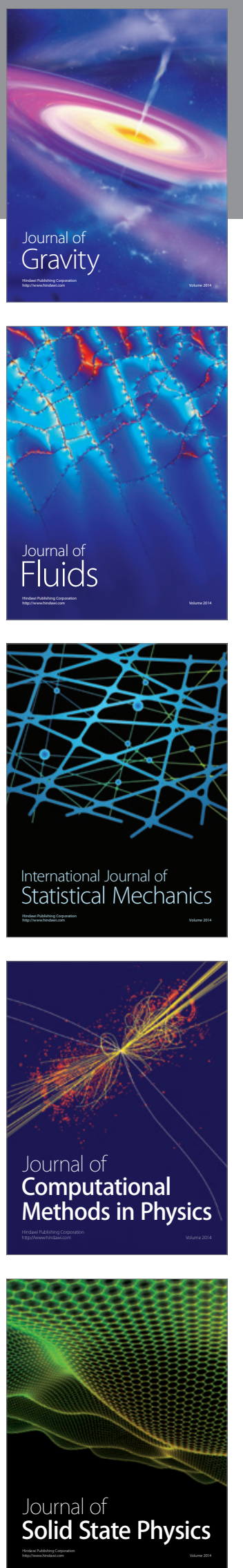

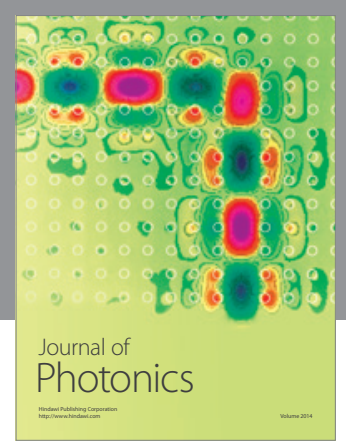

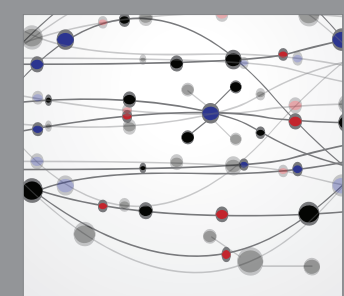

The Scientific World Journal
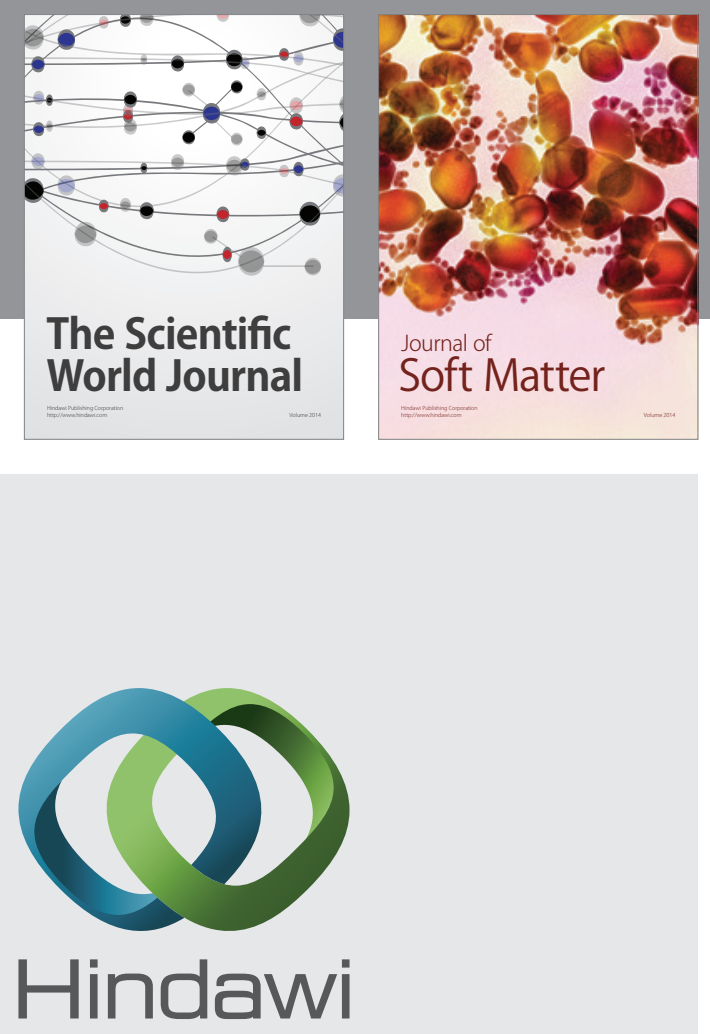

Submit your manuscripts at

http://www.hindawi.com
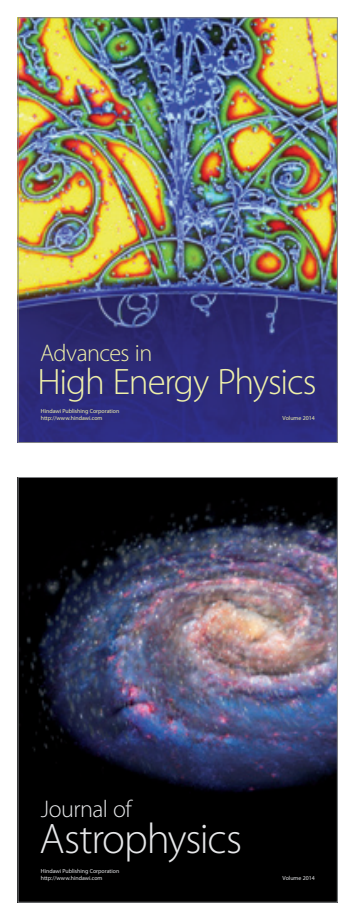
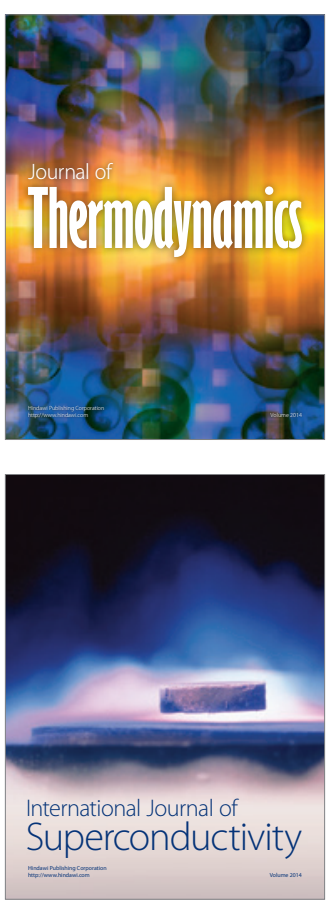
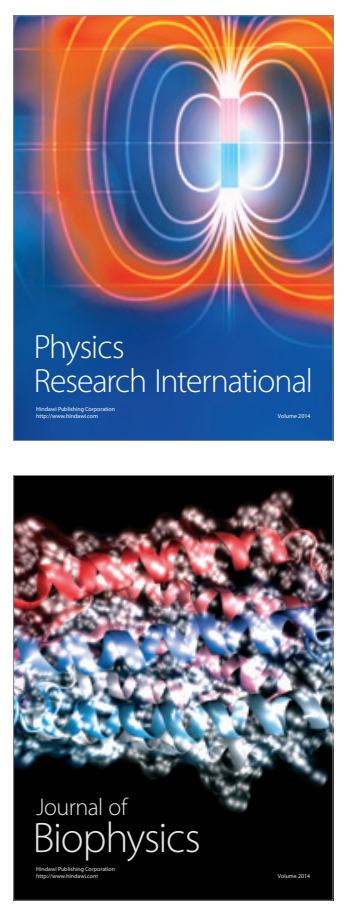
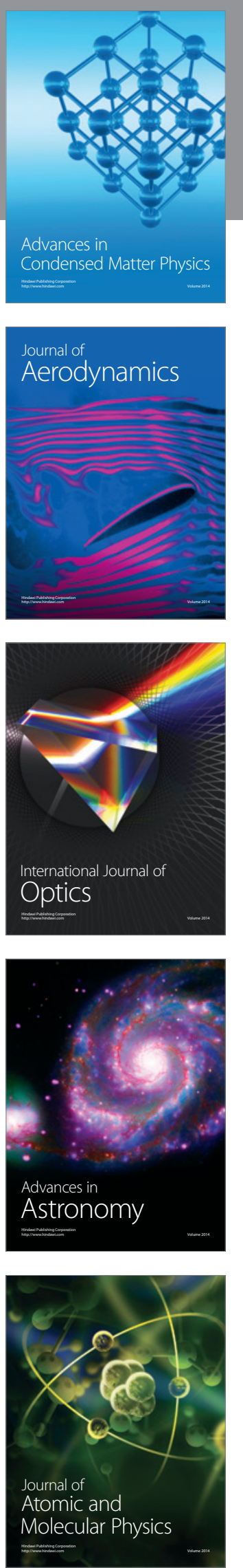